\title{
The SLC6A14 gene shows evidence of association with obesity
}

\author{
Elina Suviolahti, ${ }^{1,2}$ Laura J. Oksanen,, ${ }^{1,3}$ Miina Öhman, ${ }^{2,4}$ Rita M. Cantor, $, 1,5$ \\ Martin Ridderstråle, ${ }^{6}$ Tiinamaija Tuomi, ${ }^{3,7}$ Jaakko Kaprio, ${ }^{8,9}$ Aila Rissanen, ${ }^{10}$ \\ Pertti Mustajoki, ${ }^{11}$ Pekka Jousilahti, ${ }^{12}$ Erkki Vartiainen, ${ }^{12}$ Kaisa Silander, ${ }^{2}$ Riika Kilpikari, ${ }^{2}$ \\ Veikko Salomaa, ${ }^{12}$ Leif Groop, ${ }^{6}$ Kimmo Kontula, ${ }^{3}$ Leena Peltonen, ${ }^{1,2,13}$ \\ and Päivi Pajukanta ${ }^{1}$
}

${ }^{1}$ Department of Human Genetics, University of California, Los Angeles, Los Angeles, California, USA

${ }^{2}$ Department of Molecular Medicine, National Public Health Institute, Helsinki, Finland

${ }^{3}$ Department of Medicine, Helsinki University Central Hospital, Helsinki, Finland

${ }^{4}$ Department of Internal Medicine, University of Michigan, Ann Arbor, Michigan, USA

${ }^{5}$ Department of Pediatrics, University of California, Los Angeles, Los Angeles, California, USA

${ }^{6}$ Department of Endocrinology, Wallenberg Laboratory, Lund University, Malmö, Sweden

${ }^{7}$ Folkhälsan Research Institute, Helsinki, Finland

${ }^{8}$ Finnish Twin Cohort Study, Department of Public Health, University of Helsinki, Helsinki, Finland

${ }^{9}$ Department of Mental Health and Alcohol Research, National Public Health Institute, Helsinki, Finland

${ }^{10}$ Obesity Research Unit, Helsinki University Central Hospital, Helsinki, Finland

${ }^{11}$ Department of Medicine, Peijas Hospital, Vantaa, Finland

${ }^{12}$ Department of Epidemiology and Health Promotion, National Public Health Institute, Helsinki, Finland

${ }^{13}$ Department of Medical Genetics, University of Helsinki, Helsinki, Finland

In our previous genome-wide scan of Finnish nuclear families, obesity was linked to chromosome Xq24. Here we analyzed this $15-\mathrm{Mb}$ region by genotyping 9 microsatellite markers and 36 single nucleotide polymorphisms (SNPs) for 11 positional and functional candidate genes in an extended sample of 218 obese Finnish sibling pairs (sibpairs) $\left(\mathrm{BMI}>30 \mathrm{~kg} / \mathrm{m}^{2}\right)$. Evidence of linkage emerged mainly from the obese male sibpairs, suggesting a gender-specific effect for the underlying gene. By constructing haplotypes among the obese male sibpairs, we restricted the region from $15 \mathrm{Mb}$ to $4 \mathrm{Mb}$, between markers DXS8088 and DXS8067. Regional functional candidate genes were tested for association in an initial sample of 117 cases and 182 controls. Significant evidence was observed for association for an SNP in the $3^{\prime}$-untranslated region of the solute carrier family 6 member $14(S L C 6 A 14)$ gene $(P=0.0002)$ and for SNP haplotypes of the SLC6A14 gene $(P=0.0007-0.006)$. Furthermore, an independent replication study sample of 837 cases and 968 controls from Finland and Sweden also showed significant differences in allele frequencies between obese and non-obese individuals $(P=0.003)$. The SLC6A14 gene is an interesting novel candidate for obesity because it encodes an amino acid transporter, which potentially regulates tryptophan availability for serotonin synthesis and thus possibly affects appetite control.

J. Clin. Invest. 112:1762-1772 (2003). doi:10.1172/JCI200317491.

\section{Introduction}

Obesity poses a serious health problem in the Western societies due to the higher risk for related disorders

Received for publication November 27, 2002, and accepted in revised form October 14, 2003.

Address correspondence to: Päivi Pajukanta, Department of Human Genetics, Gonda (Goldschmied) Neuroscience and Genetics Research Center, 695 Charles E. Young Drive South, David Geffen School of Medicine at UCLA, Los Angeles, California 90095-7088, USA. Phone: (310) 794-9802;

Fax: (310) 794-5446; E-mail: ppajukanta@mednet.ucla.edu.

Conflict of interest: The authors have declared that no conflict of interest exists.

Nonstandard abbreviations used: coronary heart disease (CHD); maximum likelihood score (MLS); dizygotic (DZ); single nucleotide polymorphism (SNP); solute carrier family 6 member 14 (SLC6A14); sibling pair (sibpair); familial combined hyperlipidemia (FCHL); linkage disequilibrium (LD); National Center for Biotechnology Information (NCBI); identity-bydescent (IBD); 3'-untranslated region (3'-UTR); large neutral amino acid (LNAA). such as type 2 diabetes, coronary heart disease (CHD), hypertension, osteoarthritis, and certain cancers (1). A significant genetic component has been documented in the etiology of obesity (refs. 2, 3, 4; reviewed in ref. 5). Cases of obesity with a monogenic origin are rare (reviewed in ref. 6), whereas common forms of obesity are most likely caused by multiple genetic and environmental factors, and their interactions.

In Finland, as well as in other Western societies, obesity has become more prevalent during the last three decades $(7,8)$. Currently, more than $20 \%$ of the Finnish population has a BMI greater than $30 \mathrm{~kg} / \mathrm{m}^{2}$ and can thus be considered obese (9). The Finnish population is a suitable study sample for detecting candidate genes for obesity due to the high prevalence of this disorder and the relative genetic and environmental homogeneity of the population (10).

A locus on chromosome Xq24 was linked to obesity with a maximum likelihood score (MLS) of 3.1 in our 
previous genome-wide scan of Finnish obese nuclear families (11). This X-chromosome locus may be of particular interest when searching for genes predisposing to obesity, because obesity and related phenotypes, such as fat distribution, fat percentage, and leptin levels, appear to be influenced by gender $(12,13)$. Furthermore, quantitative genetic modeling of twin data from monozygotic, same-sex dizygotic (DZ) and opposite-sex DZ pairs indicates that sex-specific genetic influences on BMI are seen in adolescent and young adult population-based twin samples, in addition to genetic factors common to both sexes $(14,15)$.

None of the other reported genome scans of obesity have revealed a significant linkage to Xq24. However, two separate studies of obesity detected suggestive linkage in this region with lod scores of 1.4 (16) and 2.0 (17). It is worth noting that most genome scans related to obesity have used quantitative traits and did not include the sex chromosomes in their analysis, with the exception of two studies $(18,19)$. The reason for excluding X-chromosome scan data may be the lack of computer programs for such analyses (20). Interestingly, however, Monaghan et al. reported a woman with Prader-Willi-like syndrome, which features obesity as one of its major symptoms, carrying an Xq23-25 duplication (21).

In this study, we investigated the $\mathrm{Xq} 22-24$ region by first haplotyping microsatellite markers and single nucleotide polymorphisms (SNPs) in candidate genes in obese Finnish siblings. After identifying initial evidence for shared haplotypes in a 4-Mb region, we tested SNPs and microsatellites in the region in an initial case-control sample. We found significant evidence of association between obesity and the solute carrier family 6 member 14 (SLC6A14) gene $(P=0.0002)$. Importantly, an independent replication sample of 837 cases and 968 controls from Sweden and Finland also showed differences in allele frequencies between obese and non-obese individuals $(P=0.003)$. This is the first report to our knowledge implicating SLC6A14 in obesity.

\section{Methods}

Study samples. The study sample consisted of 218 obese sibling pairs (sibpairs) (BMI $\geq 30 \mathrm{~kg} / \mathrm{m}^{2}$ ) from 184 Finnish nuclear families. Of these, 193 sibpairs from 166 families participated in our previous genome scan for obesity (11). In addition, to increase the power to identify an association, we included 25 additional Finnish obese sibpairs (BMI $\geq 30 \mathrm{~kg} / \mathrm{m}^{2}$ ) from families ascertained for familial combined hyperlipidemia (FCHL) or low serum HDL levels in the analysis of the stage 2 markers (for definition of stages 1 and 2, see Results). The origin of and the diagnostic criteria for these families have been described earlier $(22,23)$. These Finnish FCHL and HDL families showed suggestive evidence of linkage with this same $\mathrm{X}$-chromosomal region, with a lod score of 1.5 (23).

For the initial association study, one obese male from each of the 184 original nuclear families, where available, was selected as a case $(n=117)$. A group of unrelated normal-weight Finnish men $(n=182)$ were selected as controls based on their BMI of $27 \mathrm{~kg} / \mathrm{m}^{2}$ or less and age of 40 years or more (Table 1).

An independent replication sample of 837 cases (416 females and 421 males) and 968 controls (381 females and 587 males) was collected from Finland and Sweden to test the associated SLC6A14 variants for association (Table 1). In detail, 568 obese Finnish cases were recruited from obesity clinics in Helsinki $(n=207)$, from the National FINRISK97 cohort in Finland $(n=200)(24)$, and from the Botnia study $(n=161)(25$, 26). In addition, a total of 269 Swedish obese subjects were recruited from the obesity clinic in Malmö, Sweden. All the obese subjects from the obesity clinics in Finland and Sweden had a BMI values of $30 \mathrm{~kg} / \mathrm{m}^{2}$ or more and had undergone bariatric surgery or participated in a weight reduction program to treat their obesity. These patients had contacted the obesity clinic on their own initiative and when first contacting the clinic, the patients had BMI values of $40 \mathrm{~kg} / \mathrm{m}^{2}$ or more. The obese cases selected from the National FINRISK97 cohort had BMI values of $35 \mathrm{~kg} / \mathrm{m}^{2}$ or more.

\section{Table 1}

Mean age and BMI of subjects in the initial linkage and association study and the analysis of the additional SLC6A14 SNPs, and in the replication sample

\begin{tabular}{|c|c|c|c|c|c|c|}
\hline & \multirow{2}{*}{$\begin{array}{l}\text { Affected individuals } \\
\text { in the linkage study }\end{array}$} & \multicolumn{3}{|c|}{ Association study } & \multicolumn{2}{|c|}{ Additional analyzed SNPs } \\
\hline & & Cases & Controls & Controls (subset) & Cases & Controls \\
\hline Number (M/F) & $398(157 / 241)$ & $117 \mathrm{M}$ & $182 \mathrm{M}$ & $67 \mathrm{M}$ & $180 \mathrm{M}$ & $180 \mathrm{M}$ \\
\hline Age (years) & $50.7 \pm 8.4$ & $50.3 \pm 8.1$ & $56.8 \pm 8.3$ & $51.3 \pm 11.0$ & $51.5 \pm 9.3$ & $50.4 \pm 9.4$ \\
\hline $\operatorname{BMI}\left(\mathrm{kg} / \mathrm{m}^{2}\right)$ & $35.8 \pm 5.9$ & $36.2 \pm 6.1$ & $24.1 \pm 2.2$ & $24.1 \pm 2.1$ & $38.0 \pm 6.6$ & $23.4 \pm 1.1$ \\
\hline
\end{tabular}

\begin{tabular}{lcccccc} 
& \multicolumn{4}{c}{ Replication sample } \\
& Cases & All & \multicolumn{2}{c}{ Finnish } & \multicolumn{2}{c}{ Swedish } \\
Number $(\mathrm{M} / \mathrm{F})$ & $837(421 / 416)$ & $968(587 / 381)$ & $568(349 / 219)$ & $709(514 / 195)$ & $269(72 / 197)$ & $259(73 / 186)$ \\
Age $($ years $)$ & $48.5 \pm 12.3$ & $49.1 \pm 11.3$ & $51.5 \pm 10.7$ & $52.1 \pm 9.6$ & $41.9 \pm 12.2$ & $44.8 \pm 14.0$ \\
BMI $\left(\mathrm{kg} / \mathrm{m}^{2}\right)$ & $39.8 \pm 6.6$ & $23.0 \pm 1.4$ & $38.7 \pm 6.4$ & $23.4 \pm 1.5$ & $41.1 \pm 6.9$ & $22.3 \pm 1.7$ \\
\hline
\end{tabular}

Age and $\mathrm{BMI}$ values are given as mean \pm standard deviation. $\mathrm{M}$, male; $\mathrm{F}$, female. 


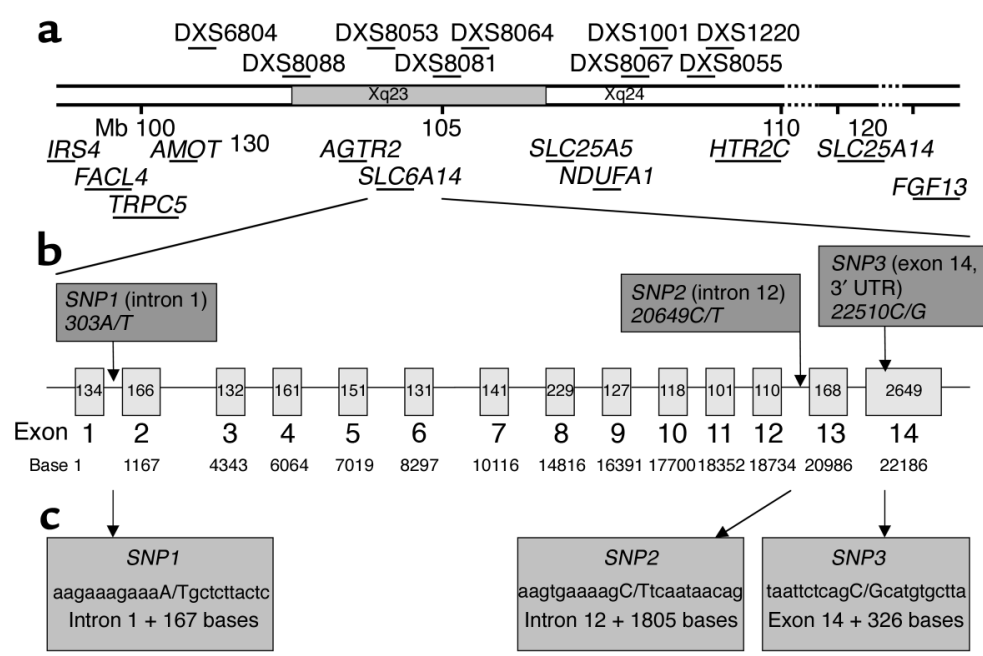

Figure 1

(a) The genes and microsatellite markers on chromosome Xq22-26 selected for this study. Distances and order are based on the public NCBI and commercial Celera Genomics databases. (b) Structure of the SLC6A14 gene and locations of the genotyped SNPs. (c) SNPs, their locations in the SLC6A14 gene, and the surrounding sequence (SNP nucleotides are capitalized).

The obese male cases selected from the Botnia study had BMI values of $30 \mathrm{~kg} / \mathrm{m}^{2}$ or more and each had at least one additional sibling with a BMI of $30 \mathrm{~kg} / \mathrm{m}^{2}$ or more. Altogether, 968 lean control subject with BMI values of 25 or less were recruited from the same geographical regions as the obese cases (Table 1).

Of the 49 new SLC6A14 variants identified in the sequencing analysis, 5 were tested for linkage disequilibrium (LD) and association in 113 of the original male cases of the initial association study and in 67 additional extremely obese males from the obesity clinics in Finland (total $n=180$ ). For these analyses, 180 male controls $\left(\mathrm{BMI} \leq 25 \mathrm{~kg} / \mathrm{m}^{2}\right)$ were selected from the National FINRISK97 cohort (24). These 180 controls were part of the Finnish replication study sample (see above).

The study protocols were approved by the ethics committees of the participating centers, and each study subject gave a written informed consent.

SNP and marker selection. Microsatellite markers and SNPs were selected in a region spanning $15 \mathrm{Mb}$ on chromosome X (Figure 1a) that has previously been linked to obesity in this same study sample (11). Public (National Center for Biotechnology Information [NCBI]; http://www.ncbi.nlm.nih.gov) and commercial (Celera Genomics; http://www.celera.com) databases were used to find polymorphisms in the following genes: insulin receptor substrate 4 (IRS4), fatty-acid-CoA ligase, longchain 4 (FACL4), transient receptor potential cation channel, subfamily $\mathrm{C}$, member 5 (TRPC5), angiomotin (AMOT), angiotensin receptor 2 (AGTR2), solute carrier family 6 member 14 (SLC6A14), solute carrier family 25 (mitochondrial carrier; adenine nucleotide translocator), member 5 (SLC25A5), NADH dehydrogenase (ubiquinone) 1 alpha subcomplex, $1,7.5 \mathrm{kDa}$ (NDUFA1), 5-hydroxytryptamine (serotonin) receptor 2C (HTR2C), solute carrier family 25 (mitochondrial carrier, brain), member 14 (SLC25A14) and fibroblast growth factor 13 (FGF13). These genes were selected based on their potential functional significance or physical position. The physical order of the markers and genes was determined according to the NCBI and Celera Genomics databases.

The SNPs (two to four per gene) were chosen primarily in coding regions and in genomic regions conserved between human and mouse. Comparisons of the genomic sequences (gene $\pm 10 \mathrm{~kb}$ ) between these two species were performed using the Pipmaker program (27). We also aimed to cover the genes with evenly spaced SNPs, avoiding gaps larger than $20 \mathrm{~kb}$ within a gene. First, samples from eight control individuals of Finnish origin were sequenced to confirm the selected SNPs. Thus, in cases where no heterozygotes were detected among these eight individuals, the particular SNP was discarded. In addition, when adjacent SNPs were in complete LD in the eight individuals, only one was selected for further studies. The complete list of markers and SNPs genotyped in this study is presented on our website (http://www.ktl.fi/mols/obe), and the novel SNPs characterized in this study will be submitted to public databases (NCBI).

Genotyping. Microsatellite markers were genotyped using the ABI Prism 3700 DNA Analyzer and were analyzed with the Genotyper 3.7 software (Applied Biosystems Inc., Foster City, California, USA) as described earlier (11). A pyrosequencing technique was applied for the SNP genotyping using the PSQ96 instrument and the SNP Reagent kit (Pyrosequencing AB, Uppsala, Sweden) (28) in stages 1 and 2 (for definition of these stages, see Results), as well as in the initial association study. The SNPs of the large replication sample as well as the five additional SNPs were genotyped using homogenous Mass Extension reaction on the Mass Array System (Sequenom, San Diego, California, USA), as specified by manufacturer's instructions.

Sequencing of the SLC6A14 gene. We sequenced the entire SLC6A14 gene, $800 \mathrm{bp}$ of its putative promoter, and $2 \mathrm{~kb}$ downstream from the $3^{\prime}$ end of SLC6A14 (including an adjacent predicted gene, LOC203413) in 20 obese male individuals (for selection criteria of the obese individuals, see Results). Sequencing was performed according to the BigDye Terminator Cycle Sequencing protocol (Applied Biosystems Inc.), with minor modifications, and the samples were separated with the automated DNA sequencer ABI 377XL (Applied Biosystems Inc.). Sequence contigs were assembled through use of Sequencher software (Gene Codes Corp., Ann Arbor, Michigan, USA).

Statistical analysis. To test the microsatellite markers and SNPs for linkage, we used a nonparametric affect- 
ed sibpair approach using the MAPMAKER/SIBS 2.0 program (29). This method of analysis estimates the proportion of allele sharing on the $\mathrm{X}$ chromosome in three kinds of sibpairs separately: male-male, malefemale and female-female. For X-chromosome markers, the MLS has only one degree of freedom, because one can only evaluate identity-by-descent (IBD) of chromosomes inherited from the mother's side. Thus, an affected sibpair can share either 0 or 1 allele IBD. The option "all pairs weighted" was chosen to obtain information also from families having more than two obese siblings. Marker allele frequencies were estimated from all individuals using the DOWNFREQ program (30). Haplotypes were constructed using the GENEHUNTER program, version 1.3 (31), for the male sibpairs and for male case and control subjects. Haplotyping of X-chromosome markers in males is unambiguous, since males are hemizygous for the $\mathrm{X}$ chromosome.

LD between the marker genotypes was tested using the Genepop v3.1b program, option 2 (http://wbiomed.curtin.edu.au/genepop). In this program, one test of association is performed for genotypic $\mathrm{LD}$, and the null hypothesis is that genotypes at one locus are independent from genotypes at the other locus. Then the program creates contingency tables for all pairs of loci and conducts Fisher's exact test for each two-by-two table. In men, the phase information is complete on the $\mathrm{X}$ chromosome, and the haploid data could be used reliably to test for $\mathrm{LD}$ using this Genepop program.

The DISLAMB program version 2.1 was used to test for association; that is, differences in the distributions of allele frequencies of SNPs and SNP haplotypes between cases and controls (32). A $\chi^{2}$ test was applied for the diallelic markers, and a likelihood ratio test was used for multiallelic markers.

In the replication study sample, one overall analysis of males and females of Swedish and Finnish origin was performed to test for association with obesity with the multilocus genotypes of the two X-linked SNPs (SNP2 and SNP3), using the option 12 of the Mendel program (33).

In this analysis, empiric $P$ values were calculated by permuting the case and control labels within the categories of Swedish males, Swedish females, Finnish males, and Finnish females simultaneously, and combining the data for each permutation to establish a distribution of possible genotypes for cases and controls.

\section{Results}

Genotyping the Xq24 markers. We had earlier linked a 15$\mathrm{Mb}$ region on chromosome Xq24 to obesity in a genomewide scan of Finnish obese nuclear families (11). Here we investigated the region by genotyping additional microsatellite markers and SNPs for regional candidate genes to test them for linkage and association. Our aim was not to cover all the genes located in the $15-\mathrm{Mb}$ region, but to target relevant functional candidate genes for obesity. In addition to the regional markers, we tested two compelling candidate genes, SLC25A14 and FGF13, located 9.1 and $17 \mathrm{Mb}$, respectively, from the linked region.
In stage 1, we genotyped 36 SNPs and nine microsatellite markers in 100 obese sibpairs and available parents in a $15-\mathrm{Mb}$ region between the IRS4 and HTR2c genes, and in the SLC25A14 and FGF13 genes. The complete linkage data are given at our website (www.ktl.fi/ mols/obe). We observed two interesting findings in these analyses. First, most of the allele sharing among obese siblings occurred over an 8-Mb region between marker DXS6804 and the HTR2C gene. Second, we found that the obese male sibpairs contributed most to the linkage signal in this region (Table 2).

In stage 2, the genotyping was further extended to 118 additional sibpairs for the nine multiallelic markers and 17 SNPs in the AGTR2, SLC6A14, SLC25A5, NDUFA1, and HTR2C genes located in the $8-\mathrm{Mb}$ region where most of the allele sharing occurred in stage 1 . Results from the combined analysis of the stage 1 and stage 2 study samples provided some evidence for linkage to this region, but did not narrow down the region (Table 2).

Haplotyping. Because most of the linkage evidence for the SNPs and markers in the Xq22-24 region emerged from obese male sibpairs, we analyzed haplotypes of all male sibpairs in the study to investigate whether any were shared by the obese male sibpairs. We detected three putative shared haplotypes in the SLC6A14 gene. A total of 16 families out of 26 shared the same 303A20649C-22510G haplotype of the SLC6A14 SNPs, three families shared the 303A-20649T-22510C haplotype and two families shared the 303T-20649C-22510G haplotype (Figure 2). These shared haplotypes of the SLC6A14 gene partially extended to the neighboring markers (DXS8053 and DXS8081) and genes (AGTR2, SLC25A5 and NDUFA1). Interestingly, two families shared a $3-\mathrm{Mb}$ haplotype from marker DXS8053 to the NDUFA1 gene, and three families shared a 1-Mb haplotype from the AGTR2 gene to marker DXS8081 (Figure 2). There was also a shared haplotype (-2328C-(-)935C-2028C-3169A) within the SLC25A5 gene, located $1.1 \mathrm{Mb}$ from the SLC6A14 gene (the minus sign before the nucleotide indicates that the SNP is located $5^{\prime}$ from the transcription starting site). This haplotype was detected in 14 families, but it was only partially shared among the SLC6A14 303A-20649C-22510G haplotype carriers (Figure 2). In summary, the haplotype data suggested sharing within the SLC6A14 gene, although it was not specific to this gene. Subsequently, we selected 11 informative SNPs for the SLC6A14 gene and for its two neighboring genes (AGTR2 and SLC25A5) and also genotyped three microsatellite markers (DXS8081, DXS8053 and DXS8064) located in this region for an association analysis.

Initial association study. The obese nuclear families of this study are not optimal for a family-based association analysis, since parental genotype information is often missing. To search for association with a more powerful approach, we used a case-control sample in the region showing initial evidence of shared haplotypes. Three SNPs of the SLC6A14 gene were genotyped 
Table 2

Single-point MLS of microsatellite markers and SNPs genotyped in stages 1 and 2 of the linkage and haplotype analysis for all study subjects and for male pairs

\begin{tabular}{|c|c|c|c|c|c|}
\hline Marker & & $\begin{array}{c}\text { MLS for all } \\
\text { study subjects } \\
\text { (males only) stage } 1\end{array}$ & $\begin{array}{c}\text { MLS for all } \\
\text { study subjects } \\
\text { (males only) stage } 2\end{array}$ & Heterozygosity & $\begin{array}{c}\text { Intermarker } \\
\text { distance (Mb) }\end{array}$ \\
\hline DXS6804 & & $1.15(1.15)$ & $0.14(0.14)$ & 0.68 & \\
\hline DXS8088 & & $0.07(0.07)$ & 0.0 & 0.67 & +1.2 \\
\hline \multirow[t]{4}{*}{ AGTR2 } & SNP1 & $0.60(0.49)$ & $0.19(0.10)$ & 0.50 & +0.8 \\
\hline & SNP2 & $0.52(0.32)$ & $0.24(0.04)$ & 0.50 & \\
\hline & SNP3 & $1.43(0.43)$ & $1.18(0.32)$ & 0.45 & \\
\hline & SNP4 & $2.30(1.30)$ & $1.50(0.64)$ & 0.49 & \\
\hline DXS8053 & & $1.46(0.70)$ & $1.03(0.44)$ & 0.49 & +0.3 \\
\hline \multirow[t]{3}{*}{ SLC6A14 } & SNP1 & $1.27(1.08)$ & $1.15(0.91)$ & 0.35 & +0.03 \\
\hline & SNP2 & $0.11(0.0)$ & $0.22(0.21)$ & 0.40 & \\
\hline & SNP3 & $0.47(0.0)$ & $0.62(0.31)$ & 0.47 & \\
\hline DXS8081 & & $0.75(0.75)$ & $0.29(0.21)$ & 0.63 & +0.5 \\
\hline DXS8064 & & $0.86(0.86)$ & $0.57(0.57)$ & 0.46 & +0.8 \\
\hline \multirow[t]{4}{*}{ SLC25A5 } & SNP1 & $0.19(0.07)$ & $0.43(0.43)$ & 0.48 & +1.3 \\
\hline & SNP2 & $0.53(0.43)$ & $0.19(0.19)$ & 0.36 & \\
\hline & SNP3 & $0.80(0.42)$ & $0.29(0.19)$ & 0.35 & \\
\hline & SNP4 & $0.67(0.29)$ & $0.28(0.19)$ & 0.35 & \\
\hline \multirow[t]{2}{*}{ NDUFA1 } & SNP1 & $0.12(0.08)$ & $0.71(0.65)$ & 0.50 & +0.4 \\
\hline & SNP2 & $0.25(0.05)$ & $0.17(0.16)$ & 0.07 & \\
\hline DXS8067 & & $0.68(0.68)$ & $1.44(1.44)$ & 0.63 & +0.3 \\
\hline DXS1001 & & $0.96(0.68)$ & $1.10(0.91)$ & 0.81 & +0.5 \\
\hline DXS8055 & & $0.02(0.02)$ & $0.11(0.11)$ & 0.57 & +0.6 \\
\hline DXS1220 & & $1.93(1.93)$ & $0.21(0.21)$ & 0.55 & +0.05 \\
\hline \multirow[t]{4}{*}{ HTR2C } & SNP1 & $0.55(0.48)$ & $0.11(0.10)$ & 0.31 & +0.5 \\
\hline & SNP2 & $0.68(0.48)$ & $0.10(0.10)$ & 0.41 & \\
\hline & SNP3 & $0.81(0.06)$ & $0.40(0.03)$ & 0.17 & \\
\hline & SNP4 & $0.87(0.0)$ & $1.16(0.05)$ & 0.17 & \\
\hline
\end{tabular}

MLS scores greater than 1.0 are indicated in bold.

in an initial case-control study sample of 182 independent controls and 117 obese males (the first obese male genotyped from each of the families). We only included males in this initial case-control study, as the initial linkage evidence was mostly derived from malemale pairs and the evidence for haplotypes was detected in males. In these analyses, the observed allele frequencies differed significantly between cases and controls, producing a $P$ value of 0.0002 for the SNP3 located in the $3^{\prime}$-untranslated region (3'-UTR) $(22510 C / G)$ of the SLC6A14 gene (allele frequencies of 0.70 versus 0.46 for cases versus controls for SNP3 G allele; Table 3). Suggestive evidence for association $(P=0.07)$ was also detected for the SNP2 in intron 12 $(20649 \mathrm{C} / \mathrm{T})$ of the SLC6A14 gene $(0.72$ versus 0.61 for cases versus controls for SNP2 C allele; Table 3). Interestingly, the more frequent allele of both SNPs was associated with obesity. When these two intragenic SNPs were combined into haplotypes, the difference in allele frequencies remained significant $(P=0.0007)$, as it did when all three SNPs of the SLC6A14 gene were combined $(P=0.006$; Table 3$)$. The obesity-associated haplotype alleles (20649C-22510G and 303A-20649C$22510 \mathrm{G}$ ) were also the major alleles in the study sample (frequencies of 0.70 and 0.52 for cases and 0.46 and 0.33 for controls, respectively).
Because haplotype sharing was not specific to the SLC6A14 gene (Figure 2), we also genotyped eight SNPs in the neighboring genes, AGTR2 and SLC25A5, as well as three microsatellite markers, DXS8088, DXS8081, and DXS8064. The allele frequencies for the SNPs in the AGTR2 and SLC25A5 genes did not differ between male cases $(n=117)$ and male controls $(n=67)$ (Table 4). No additional controls were genotyped. The allele frequencies of marker DXS8081, located in the vicinity of the SLC6A14 gene, showed a small difference between cases and controls $(P=0.05)$ (Table 4$)$, supporting the evidence obtained regarding SLC6A14 in the association analysis.

Replication study. The obesity-associated SNP2 and SNP3 were genotyped in an independent replication sample of 837 cases (416 females and 421 males) and 968 controls ( 381 females and 587 males) from Finland and Sweden. Again, significant differences in allele frequencies were detected for SNP3 between the two groups $(P=0.003)$, with the $C$ allele being more common among obese subjects (allele frequencies of 0.49 in cases and 0.43 in controls; Table 5). For SNP2, the $T$ allele was more frequent in cases than in controls, but the difference was not statistically significant $(0.38$ versus 0.35 for cases versus controls for $T$ allele; $P=0.08$ ). Furthermore, in one overall analysis of multilocus 


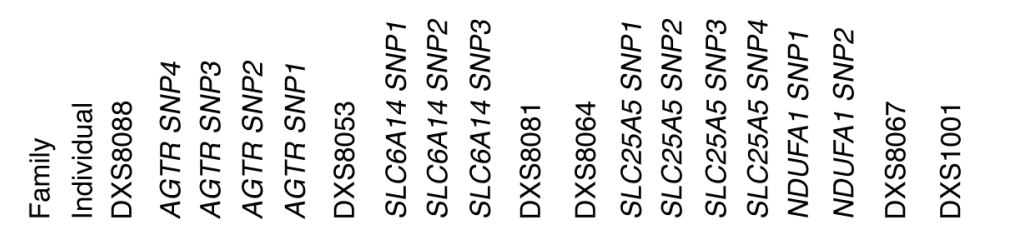

\begin{tabular}{|c|c|c|c|c|c|c|c|c|c|c|c|c|c|c|c|c|c|c|c|c|c|}
\hline $\begin{array}{l}1 \\
1\end{array}$ & $\begin{array}{l}1 \\
2\end{array}$ & $\begin{array}{l}8 \\
8\end{array}$ & $\begin{array}{l}\mathrm{T} \\
\mathrm{T}\end{array}$ & $\begin{array}{l}G \\
G\end{array}$ & $G$ & $\begin{array}{l}\mathrm{A} \\
\mathrm{A}\end{array}$ & $\begin{array}{l}2 \\
2\end{array}$ & $\begin{array}{l}\text { A } \\
A\end{array}$ & $\begin{array}{l}\mathrm{C} \\
\mathrm{C}\end{array}$ & $\begin{array}{l}G \\
G\end{array}$ & $\begin{array}{l}4 \\
4\end{array}$ & $\begin{array}{l}7 \\
7\end{array}$ & $\begin{array}{l}\bar{C} \\
T\end{array}$ & $\begin{array}{l}\text { C } \\
T\end{array}$ & $\begin{array}{l}C \\
T\end{array}$ & $\begin{array}{l}A \\
G\end{array}$ & $\begin{array}{l}\mathrm{G} \\
\mathrm{C}\end{array}$ & $\begin{array}{l}\mathrm{T} \\
\mathrm{T}\end{array}$ & $\begin{array}{l}6 \\
6\end{array}$ & $\begin{array}{l}1 \\
0\end{array}$ & Allele sharing within family \\
\hline 2 & 1 & 8 & $\mathrm{~T}$ & G & $T$ & $A$ & 6 & A & C & G & 5 & 9 & $\mathrm{~T}$ & $C$ & C & $A$ & G & $\mathrm{T}$ & 6 & $\overline{1}$ & No allele sharing within family \\
\hline 2 & 2 & 9 & $\mathrm{~T}$ & G & G & $A$ & 4 & A & $\mathrm{C}$ & G & 6 & 6 & $\mathrm{~T}$ & $T$ & $T$ & $G$ & $\mathrm{G}$ & $\mathrm{T}$ & 7 & 1 & Allele sharing between families \\
\hline 3 & 1 & 7 & $\mathrm{~T}$ & $\bar{G}$ & $\bar{T}$ & A & 6 & A & C & G & 4 & 7 & $\bar{T}$ & $\mathrm{~T}$ & $\mathrm{~T}$ & $G$ & G & $\mathrm{T}$ & 6 & 1 & Allele sharing between families \\
\hline 3 & 2 & 7 & $\mathrm{~T}$ & G & $\mathrm{T}$ & A & 6 & A & C & G & 4 & 7 & $\mathrm{~T}$ & $\mathrm{~T}$ & $\mathrm{~T}$ & G & $\mathrm{G}$ & $\mathrm{T}$ & 6 & 0 & Allele sharing between families \\
\hline 4 & 1 & 6 & $\mathrm{~T}$ & G & $T$ & A & 6 & A & C & G & 5 & 6 & C & $\mathrm{C}$ & $\mathrm{C}$ & A & G & $\mathrm{T}$ & 8 & 2 & Allele sharing between families \\
\hline 4 & 2 & 6 & $\mathrm{~T}$ & $\mathrm{G}$ & $\mathrm{T}$ & A & 6 & A & $\mathrm{C}$ & G & 5 & 6 & $\mathrm{C}$ & $\mathrm{C}$ & $\mathrm{C}$ & A & G & $\mathrm{T}$ & 8 & 2 & 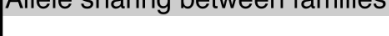 \\
\hline 5 & 1 & 8 & C & A & G & G & 0 & A & C & G & 5 & 5 & C & C & $\mathrm{C}$ & A & G & $\mathrm{T}$ & 8 & 4 & \\
\hline 5 & 2 & 8 & C & A & $\mathrm{G}$ & G & 6 & A & C & $G$ & 5 & 5 & C & C & C & A & G & $\mathrm{T}$ & 8 & 4 & \\
\hline 6 & 1 & 7 & $\mathrm{C}$ & A & $\mathrm{G}$ & $\mathrm{G}$ & 6 & A & C & $\mathrm{G}$ & 5 & 7 & $\mathrm{~T}$ & $\mathrm{C}$ & $\mathrm{C}$ & $A$ & $\mathrm{G}$ & $\mathrm{T}$ & 7 & 1 & \\
\hline 6 & 2 & 7 & $\mathrm{C}$ & A & G & $\mathrm{G}$ & 6 & A & $\mathrm{C}$ & G & 5 & 7 & $\mathrm{~T}$ & $\mathrm{C}$ & $\mathrm{C}$ & A & G & $\mathrm{T}$ & 7 & 1 & \\
\hline 7 & 1 & 8 & $\mathrm{C}$ & A & G & $\mathrm{G}$ & 6 & A & C & $G$ & 6 & 7 & C & $C$ & C & A & C & 0 & 4 & 0 & \\
\hline 7 & 2 & 8 & C & A & G & $G$ & 6 & A & C & G & 6 & 7 & C & $\mathrm{C}$ & C & A & C & 0 & 4 & 1 & \\
\hline 7 & 3 & 8 & C & A & G & $\mathrm{G}$ & 6 & A & C & G & 6 & 7 & C & $\mathrm{C}$ & C & A & C & 0 & 4 & 0 & \\
\hline 8 & 1 & 6 & $\mathrm{C}$ & $A$ & $\bar{G}$ & $\bar{G}$ & 4 & A & C & 0 & 6 & 7 & $T$ & $T$ & $T$ & $G$ & C & $\mathrm{T}$ & 7 & 5 & \\
\hline 8 & 2 & 6 & C & A & $G$ & $G$ & 4 & A & C & $G$ & 6 & 7 & $T$ & $\mathrm{~T}$ & $\mathrm{~T}$ & $G$ & C & $\mathrm{T}$ & 7 & 5 & \\
\hline 8 & 3 & 6 & C & A & $\mathrm{G}$ & $\mathrm{G}$ & 4 & A & C & $\mathrm{G}$ & 6 & 7 & $\mathrm{~T}$ & $\mathrm{~T}$ & $\mathrm{~T}$ & $\mathrm{G}$ & C & $\mathrm{T}$ & 7 & 5 & \\
\hline 9 & 1 & 9 & $\mathrm{~T}$ & $G$ & $\bar{T}$ & A & 4 & A & C & G & 6 & 7 & $T$ & $\bar{T}$ & $\mathrm{~T}$ & $G$ & C & $\mathrm{T}$ & 6 & 4 & \\
\hline 9 & 2 & 9 & $\mathrm{~T}$ & $\mathrm{G}$ & $\mathrm{T}$ & A & 4 & A & C & G & 6 & 0 & $\mathrm{~T}$ & $\mathrm{~T}$ & $\mathrm{~T}$ & $\mathrm{G}$ & C & $\mathrm{T}$ & 6 & 4 & \\
\hline 10 & 1 & 8 & $\mathrm{~T}$ & $\mathrm{G}$ & $\mathrm{T}$ & A & 4 & A & C & $\mathrm{G}$ & 6 & 9 & C & $\mathrm{C}$ & C & A & G & $\mathrm{T}$ & 6 & 3 & \\
\hline 10 & 2 & 8 & $\mathrm{~T}$ & G & I & A & 4 & A & C & G & 6 & 9 & C & $\mathrm{C}$ & $\mathrm{C}$ & A & G & $\mathrm{T}$ & 6 & 3 & \\
\hline 11 & 1 & 7 & $\bar{T}$ & $\bar{G}$ & T & A & 4 & A & C & $\mathrm{G}$ & 6 & 6 & $\mathrm{~T}$ & $\mathrm{C}$ & $\mathrm{C}$ & A & $\mathrm{G}$ & $\mathrm{T}$ & 9 & 2 & \\
\hline 11 & 2 & 7 & $\mathrm{~T}$ & $\mathrm{G}$ & $\mathrm{T}$ & A & 4 & A & C & G & 6 & 6 & $\mathrm{~T}$ & C & C & A & G & $\mathrm{T}$ & 9 & 2 & \\
\hline 12 & 1 & 7 & 0 & 0 & 0 & 0 & 4 & A & C & G & 6 & 7 & 0 & 0 & 0 & 0 & G & 0 & 6 & 1 & \\
\hline 12 & 2 & 7 & 0 & 0 & 0 & 0 & 4 & A & $\mathrm{C}$ & $\mathrm{G}$ & 6 & 7 & 0 & 0 & 0 & 0 & $\mathrm{G}$ & 0 & 6 & 1 & \\
\hline 13 & 1 & 8 & $\mathrm{C}$ & $A$ & $\mathrm{G}$ & $\mathrm{G}$ & 4 & A & $\mathrm{C}$ & $\mathrm{G}$ & 5 & 8 & $\mathrm{~T}$ & $\mathrm{~T}$ & $\mathrm{~T}$ & $G$ & $\mathrm{G}$ & $\mathrm{T}$ & 6 & 5 & \\
\hline 13 & 2 & 8 & C & A & $\mathrm{G}$ & $G$ & 4 & A & C & G & 5 & 8 & $\mathrm{~T}$ & $\mathrm{~T}$ & $\mathrm{~T}$ & $G$ & G & $\mathrm{T}$ & 6 & 5 & \\
\hline 14 & 1 & 8 & $\mathrm{~T}$ & $\mathrm{G}$ & G & A & 0 & A & C & $\mathrm{G}$ & 5 & 7 & $C$ & $\mathrm{C}$ & $\mathrm{C}$ & A & C & $\mathrm{T}$ & 6 & 0 & \\
\hline 14 & 2 & 8 & $\mathrm{~T}$ & G & $\mathrm{G}$ & A & 4 & A & C & G & 5 & 7 & C & C & C & A & C & $\mathrm{T}$ & 6 & 4 & \\
\hline 15 & 1 & 8 & $C$ & $A$ & $G$ & $G$ & 4 & A & C & $\mathrm{G}$ & 4 & 7 & $C$ & $C$ & $C$ & $A$ & $C$ & $\mathrm{~T}$ & 6 & 6 & \\
\hline 15 & 2 & 6 & $T$ & $G$ & $T$ & $A$ & 4 & A & C & G & 4 & 7 & $T$ & $T$ & $T$ & $G$ & $G$ & $\mathrm{~T}$ & 6 & 4 & \\
\hline 16 & 1 & 9 & $T$ & $G$ & $\mathrm{G}$ & 0 & 4 & A & C & $\mathrm{G}$ & 4 & 7 & C & $\mathrm{C}$ & $\mathrm{C}$ & A & G & $\mathrm{T}$ & 6 & 6 & \\
\hline 16 & 2 & 7 & $C$ & $A$ & $\mathrm{G}$ & $\mathrm{G}$ & 4 & A & C & G & 5 & 8 & C & $\mathrm{C}$ & C & A & G & $\mathrm{T}$ & 6 & 6 & \\
\hline 17 & 1 & $\underline{6}$ & C & A & $G$ & $\mathrm{G}$ & 4 & A & $\mathrm{T}$ & C & 4 & 7 & $\mathrm{~T}$ & $\mathrm{C}$ & $\mathrm{C}$ & A & $\mathrm{G}$ & $\mathrm{T}$ & 6 & 0 & \\
\hline 17 & 2 & $\underline{9}$ & $\mathrm{C}$ & A & $\mathrm{G}$ & $\mathrm{G}$ & 4 & A & $\mathrm{T}$ & C & 4 & 7 & $\mathrm{~T}$ & $\mathrm{C}$ & $\mathrm{C}$ & 0 & G & $\mathrm{T}$ & 6 & 0 & \\
\hline 18 & 1 & 8 & C & A & G & $G$ & 4 & A & $\mathrm{T}$ & C & 5 & 7 & $C$ & $\mathrm{C}$ & $\mathrm{C}$ & A & C & $\mathrm{T}$ & 6 & 3 & \\
\hline 18 & 2 & 8 & C & A & G & $\mathrm{G}$ & 4 & A & $\mathrm{T}$ & C & 5 & 7 & C & $\mathrm{C}$ & C & A & C & $\mathrm{T}$ & 6 & 3 & \\
\hline 19 & 1 & 6 & C & A & $\bar{G}$ & $\mathrm{G}$ & 4 & A & $\bar{T}$ & C & 6 & 7 & $\mathrm{C}$ & $\mathrm{C}$ & $\mathrm{C}$ & A & $\mathrm{C}$ & $\mathrm{T}$ & 6 & 3 & \\
\hline 19 & 2 & 6 & $\mathrm{C}$ & A & $\underline{G}$ & $\mathrm{G}$ & 4 & $\mathrm{~A}$ & $\mathrm{~T}$ & C & 6 & 7 & C & $\mathrm{C}$ & $\mathrm{C}$ & A & C & $\mathrm{T}$ & 6 & 3 & \\
\hline 20 & 1 & 9 & $\mathrm{~T}$ & $G$ & $\mathrm{G}$ & A & 4 & $\mathrm{~T}$ & C & $G$ & 6 & 7 & C & $\mathrm{C}$ & C & A & $\mathrm{G}$ & $\mathrm{T}$ & 6 & 5 & \\
\hline 20 & 2 & 9 & $\mathrm{~T}$ & $G$ & G & A & 4 & $\mathrm{~T}$ & C & G & 6 & 7 & C & C & C & A & G & $\mathrm{T}$ & 6 & 5 & \\
\hline 20 & 3 & 9 & $\mathrm{~T}$ & G & $\mathrm{G}$ & A & 4 & $\mathrm{~T}$ & $\mathrm{C}$ & G & 6 & 7 & C & $\mathrm{C}$ & $\mathrm{C}$ & A & G & $\mathrm{T}$ & 6 & 5 & \\
\hline 21 & 1 & $\underline{7}$ & $\mathrm{~T}$ & $G$ & G & A & 4 & $\mathrm{~T}$ & $C$ & $G$ & 4 & 6 & C & $\mathrm{C}$ & C & A & C & $\mathrm{T}$ & 5 & 4 & \\
\hline 21 & 2 & $\underline{7}$ & $\mathrm{~T}$ & $G$ & G & A & 4 & $\mathrm{~T}$ & C & $G$ & 4 & 6 & C & C & C & A & C & $T$ & 5 & 4 & \\
\hline 21 & 3 & $\underline{9}$ & $\mathrm{~T}$ & G & $\underline{T}$ & $\underline{G}$ & 4 & $\mathrm{~T}$ & C & G & $\underline{8}$ & $\underline{8}$ & 0 & $\mathrm{C}$ & C & A & C & $\mathrm{T}$ & 5 & $\underline{6}$ & \\
\hline 22 & 1 & 6 & $\mathrm{~T}$ & $\mathrm{G}$ & G & A & 5 & $\mathrm{~T}$ & $\mathrm{~T}$ & C & 6 & 7 & C & C & C & A & G & $\mathrm{T}$ & 6 & 1 & \\
\hline 22 & 2 & 6 & $\mathrm{~T}$ & $G$ & $\mathrm{G}$ & A & 5 & $\mathrm{~T}$ & $\mathrm{~T}$ & C & 6 & 7 & $\mathrm{C}$ & $\mathrm{C}$ & $\mathrm{C}$ & A & G & $\mathrm{T}$ & 6 & 1 & \\
\hline 23 & 1 & 7 & C & A & $\mathrm{G}$ & $\mathrm{G}$ & 4 & A & $C$ & $G$ & 6 & 7 & C & $\mathrm{C}$ & $\mathrm{C}$ & A & $C$ & $\mathrm{~T}$ & 6 & 4 & \\
\hline 23 & 2 & 8 & C & A & G & $G$ & 4 & A & $T$ & C & 6 & 7 & C & C & C & A & $G$ & $\mathrm{~T}$ & 8 & 1 & \\
\hline 24 & 1 & 6 & $\mathrm{~T}$ & $G$ & $T$ & $G$ & 0 & $T$ & C & $\mathrm{G}$ & 8 & 7 & C & C & C & A & G & $\mathrm{T}$ & 5 & 7 & \\
\hline 24 & 2 & 8 & $\mathrm{~T}$ & $\mathrm{G}$ & T & $A$ & 6 & $A$ & $\mathrm{C}$ & $\mathrm{G}$ & 5 & 0 & C & $\mathrm{C}$ & $\mathrm{C}$ & A & $\mathrm{G}$ & $\mathrm{T}$ & 5 & 0 & \\
\hline 25 & 1 & 8 & $\mathrm{~T}$ & $G$ & $T$ & A & 4 & A & $C$ & $G$ & 5 & 8 & C & $\mathrm{C}$ & $\mathrm{C}$ & A & $C$ & $\mathrm{~T}$ & 6 & 4 & \\
\hline 25 & 2 & 9 & $\mathrm{~T}$ & $G$ & $G$ & A & 4 & A & $T$ & C & 4 & 7 & C & $\mathrm{C}$ & C & A & $G$ & $\mathrm{~T}$ & 6 & 0 & \\
\hline 26 & 1 & 6 & $\mathrm{~T}$ & $G$ & G & $A$ & 4 & A & $C$ & $G$ & 4 & 7 & $T$ & C & C & A & $C$ & $\mathrm{~T}$ & 7 & 1 & \\
\hline 26 & 2 & 7 & 0 & $A$ & $G$ & $G$ & 6 & A & $T$ & C & 6 & 7 & C & C & C & A & C & $\mathrm{T}$ & 6 & 1 & \\
\hline
\end{tabular}

Figure 2

Haplotype sharing on Xq23-24 among male sibpairs within families and between families. The major haplotype of the SLC6A14 gene (303A20649C-22510G) is shared by 16 families and the shared haplotype partially extends to the neighboring markers.

genotypes of both tested X-linked SNPs (SNP2 and $S N P 3)$ in males and females of Swedish and Finnish origin, association with obesity was observed $(P<0.05)$. This analysis was performed using option 12 of the Mendel program (33). These analyses indicate that among all the possible genotype distributions, the probability of observing one more associated than the one seen for these data is $5 \%$. This association may result from the individual contributions of the four ethnic-gender combinations. Importantly, this overall analysis provides power to detect associations that may not be identified in the smaller groups (Table 1). Thus, combined analysis of both SNPs also provided evidence for association in the replication study sample.

When the SNPs were investigated separately in both sexes, the females were found to contribute most to the observed association $(P=0.006)$ for SNP3, with allele frequencies of 0.48 in cases $(n=416)$ and 0.41 
Table 3

Allele frequencies of the SNPs and SNP haplotypes of the SLC6A14 gene in the initial case-control analysis.

\begin{tabular}{|c|c|c|c|}
\hline \multirow[t]{2}{*}{ Variant in the SLC6A14 gene } & \multicolumn{2}{|c|}{ Allele frequency } & \multirow[t]{2}{*}{$P$} \\
\hline & $\begin{array}{c}\text { Obese } \\
(n=117)\end{array}$ & $\begin{array}{c}\text { Controls } \\
(n=182)\end{array}$ & \\
\hline $303 A / T=S N P 1$ & $0.76 / 0.24$ & $0.73 / 0.27$ & NS \\
\hline $20649 C / T=S N P 2$ & $0.72 / 0.28$ & $0.61 / 0.39$ & NS $(0.07$ \\
\hline $22510 C / G=S N P 3$ & $0.30 / 0.70$ & $0.54 / 0.46$ & 0.0002 \\
\hline \multicolumn{3}{|c|}{ Haplotypes of the $S N P 1, S N P 2$, and $S N P-3$} & 0.006 \\
\hline 303A-20649C-22510G & 0.52 & 0.33 & \\
\hline 303T-20649C-22510G & 0.17 & 0.13 & \\
\hline $303 A-20649 C-22510 C$ & 0.04 & 0.10 & \\
\hline 303T-20649C-22510C & 0.01 & 0.02 & \\
\hline 303A-20649T-22510C & 0.21 & 0.29 & \\
\hline 303T-20649T-22510C & 0.05 & 0.12 & \\
\hline \multicolumn{3}{|c|}{ Haplotypes of the SNP 2 and SNP 3} & 0.0007 \\
\hline $20649 C-22510 G$ & 0.70 & 0.46 & \\
\hline 20649C-22510C & 0.05 & 0.13 & \\
\hline 20649T-22510C & 0.26 & 0.41 & \\
\hline
\end{tabular}

SNP1 is located in Intron 1; SNP2, in intron 12; and SNP3, in the noncoding region of exon 14. Significant $P$ values are indicated in bold.

in controls $(n=381)$ for the $C$ allele. This difference was present in both Finnish and Swedish females $(P=0.08$ and 0.03 , respectively). For $S N P 2$, the difference in allele frequencies was not significant for females and males separately.

Because of the X-inactivation in females, we analyzed the females homozygous for either of the alleles in SNP2 and SNP3 separately. For SNP3, CC-genotype carriers were more prevalent in the obese group $(P=0.009)$, and a marginal difference was detected in the Swedish females alone $(P=0.10$ and 0.04 for Finnish and Swedish, respectively). No significant difference was detected for SNP2. To see if the haplotype might be acting in a recessive fashion, we tested whether the proportion of females homozygous for the SNP2 and SNP3 (i.e., genotype combinations of SNP2CC-SNP3CC,
SNP2CC-SNP3GG, SNP2TT-SNP3GG, and SNP2TTSNP3CC) was significantly different in the case and control groups. No difference was observed.

SLC6A14 gene variants. The entire SLC6A14 gene, 800 $\mathrm{bp}$ of its putative promoter, and $2 \mathrm{~kb}$ downstream from the $3^{\prime}$ end of SLC6A14 (including an adjacent predicted gene, LOC203413; GenBank accession number XM_117548) were sequenced in 20 obese male individuals. These obese males were selected from the families sharing the allele with another obese male sibling at the Xq24 locus as follows: 17 of the individuals sequenced for the region shared the obesity-associated haplotype for SNP2 and SNP3 in the SLC6A14 gene, and 3 individuals shared the allele more prevalent among the lean controls. Our sequence analysis of the SLC6A14 gene and its putative $5^{\prime}$ promoter revealed 49 variants in addition to the three SNPs genotyped earlier (Table 6). Two of the variants resided in the putative promoter; two, in the coding region; four, in the 3 '-UTR; and 41, in the intronic regions. None of the variants changed an amino acid. In the predicted gene LOC203413, we found one SNP in the 3 '-UTR of the gene and an insertion of four bases in intron 1 (Table 6). Thus a total of 54 variants were identified for the SLC6A14 region, including the three SNPs genotyped earlier, and 30 of these variants were novel, not found in the public (NCBI, LocusLink) or commercial (Celera) SNP databases previously (Table 6). A total of 23 of 30 novel variants were seen only in the group of obese males sharing the obesity-associated haplotype for SNP2 and SNP3 in the SLC6A14 gene. Five of the variants $(-715 \mathrm{C} / \mathrm{G}$ and $-298 \mathrm{~A} / \mathrm{G}$ in the putative SLC6A14 promoter, 3401C/T in intron $2,23041 \mathrm{C} / \mathrm{T}$ and $24447 \mathrm{~A} / \mathrm{G}$ in exon 14$)$ were tested for association in a subset of obese $(n=180)$ and lean $(n=180)$ Finnish males (see Methods). The allele frequencies for SNP 23041C/T in exon 14 differed between cases and controls ( 0.70 versus 0.80 for the $C$ allele; $P=0.05$ ) (Table 7). This variant is located $530 \mathrm{bp}$ downstream from SNP3. No differences were observed for the remaining four SNPs (Table 7).

Table 4

Allele frequencies of the SNPs of the AGTR2 and SLC25A5 genes and of microsatellite markers in the initial case-control analysis.

\begin{tabular}{|c|c|c|c|c|}
\hline \multirow[t]{3}{*}{ Gene } & \multirow[t]{3}{*}{ Variant/allele } & \multicolumn{2}{|c|}{ Allele frequency } & \multirow[t]{3}{*}{$P$} \\
\hline & & Obese & Initial controls & \\
\hline & & $(n=117)$ & $(n=67)$ & \\
\hline \multirow[t]{4}{*}{ AGTR2 } & $190 A / G=S N P 1$ & $0.48 / 0.52$ & $0.41 / 0.59$ & NS \\
\hline & $2822 \mathrm{G} / T=S N P 2$ & $0.65 / 0.35$ & $0.63 / 0.37$ & NS \\
\hline & $2828 A / G=S N P 3$ & $0.43 / 0.57$ & $0.52 / 0.48$ & NS \\
\hline & $5747 C / T=S N P 4$ & $0.44 / 0.56$ & $0.51 / 0.49$ & NS \\
\hline \multirow[t]{4}{*}{ SLC25A5 } & $-2328 C / T=S N P 1$ & $0.61 / 0.39$ & $0.50 / 0.50$ & NS \\
\hline & $-935 C / T=S N P 2$ & $0.78 / 0.22$ & $0.72 / 0.28$ & NS \\
\hline & $2028 C / T=S N P 3$ & $0.78 / 0.22$ & $0.73 / 0.27$ & NS \\
\hline & $3169 A / G=S N P 4$ & $0.78 / 0.22$ & $0.74 / 0.26$ & NS \\
\hline DXS8053 & $2 / 3 / 4 / 5 / 6$ & $0.04 / 0.02 / 0.66 / 0.03 / 0.25$ & $0.07 / 0 / 0.61 / 0.06 / 0.26$ & NS \\
\hline DXS8081 & $4 / 5 / 6 / 8$ & $0.30 / 0.22 / 0.47 / 0.01$ & $0.42 / 0.08 / 0.45 / 0.05$ & 0.05 \\
\hline DXS8064 & $5 / 6 / 7 / 8 / 9$ & $0.01 / 0.17 / 0.73 / 0.07 / 0.02$ & $0 / 0.15 / 0.62 / 0.16 / 0.07$ & NS \\
\hline
\end{tabular}

Significant $P$ value is indicated in bold. 
Table 5

Allele frequencies of the SNP2 and SNP3 of the SLC6A14 gene in the replication sample.

\begin{tabular}{lccc}
$\begin{array}{l}\text { The variant in the } \\
\text { SLC6A14 gene }\end{array}$ & \multicolumn{2}{c}{ Allele frequency } & $P$ \\
All individuals & $\begin{array}{c}\text { Obese } \\
(n=837)\end{array}$ & $\begin{array}{c}\text { Controls } \\
(n=968)\end{array}$ & \\
$20649 C / T=S N P 2$ & $0.62 / 0.38$ & $0.65 / 0.35$ & NS $(0.08)$ \\
$22510 C / G=S N P 3$ & $0.49 / 0.51$ & $0.43 / 0.57$ & $\mathbf{0 . 0 0 3}$ \\
Females & $\begin{array}{c}\text { Obese } \\
(n=416)\end{array}$ & $\begin{array}{c}\text { Controls } \\
(n=381)\end{array}$ & \\
20649C/T = SNP2 & $0.63 / 0.37$ & $0.67 / 0.33$ & NS \\
22510C/G = SNP3 & $0.48 / 0.52$ & $0.41 / 0.59$ & $\mathbf{0 . 0 0 6}$ \\
Males & $\begin{array}{c}\text { Obese } \\
(n=421)\end{array}$ & $\begin{array}{c}\text { Controls } \\
(n=587)\end{array}$ & \\
20649C/T = SNP2 & $0.60 / 0.40$ & $0.63 / 0.37$ & NS \\
22510C/G = SNP3 & $0.50 / 0.50$ & $0.45 / 0.55$ & NS \\
Haplotypes of the SNP 2 & & & NS \\
and SNP 3 in males3 & & & \\
20649C-22510G & 0.50 & 0.55 & \\
20649C-22510C & 0.10 & 0.08 & \\
20649T-22510C & 0.40 & 0.37 & \\
\hline
\end{tabular}

Significant $P$ values are indicated in bold.

$L D$ structure in the SLC6A14 region. LD across the SLC6A14 locus was investigated separately in men and women because the haplotypes can be unequivocally identified on male $\mathrm{X}$ chromosomes. In men, the two SNPs (SNP2 and SNP3) that showed evidence for association with obesity, as well as the five additional SNPs that were also tested for association (Table 7), were tested for LD in a subset of obese $(n=180)$ and lean $(n=180)$ Finnish males (see Methods). SNP2 and SNP3 were in tight but not complete LD $(P<0.00001)$. Both of these SNPs were also in LD with the two SNPs in exon $14(P<0.00001)$. All four SNPs are located within a $4-\mathrm{kb}$ region (Table 6 ). The LD decreases with the three SNPs in the putative promoter and in intron $2(P>0.003)$, located $17-21 \mathrm{~kb}$ from SNP2 (Table 6). In addition, microsatellites DXS8081 and DXS8064, which were the closest markers $(0.5 \mathrm{Mb}$ and $1.4 \mathrm{Mb})$ to the SNPs in exon 14 of SLC6A14, were tested for LD in the original sample set of 117 male cases and 67 male controls. DXS8081 was found to be in weak LD with SNP2 and SNP3 (P values of 0.004-0.01) and also showed some evidence for association $(P=0.05)$. No evidence for LD or association was detected with marker DXS8064. To summarize the results of the LD analyses in men, the strongest LD was found between the SNPs in the $3^{\prime}$ end of the SLC6A14 gene. There was no difference between the male cases and controls in the extent of LD.

In the 416 female cases and 381 female controls of the replication sample, the two SNPS (SNP2 and $S N P 3)$ were also found to be in tight but not complete LD $(P<0.00001)$. The genotype analysis also showed that combinations of the SNP2CT-SNP3GG (2 females) and SNP2TT-SNP3GG (0 females) genotypes are almost completely missing, suggesting that SNP2T does usually not occur on the same chromosomal DNA strand with SNP3G.

\section{Discussion}

In the present study, we investigated a region on chromosome Xq22-24 that we had previously linked to obesity in Finnish obese nuclear families (11). We have now restricted the linked region from $15 \mathrm{Mb}$ to $4 \mathrm{Mb}$ with linkage and haplotype analyses. Furthermore, we detected significant associations between obesity and SNPs in exon 14 and intron $12(P=0.0002$ and 0.07$)$ and SNP haplotypes $(P=0.0007$ and 0.006$)$ of the SLC6A14 gene in an initial case-control sample. Importantly, an independent replication sample of 837 cases and 968 controls from Finland and Sweden also showed differences in allele frequencies for SNP3 between cases and controls $(P=0.003)$, and furthermore, a combined analysis of SNP2 and SNP3 provided evidence for association $(P<0.05)$ in this replication sample.

This is the first report to our knowledge implying that the SLC6A14 gene (also known as Na- and Cldependent neutral and cationic amino acid transporter $\mathrm{B}^{0+}$ ) could be associated with obesity and body weight regulation. The SLC6A14 gene presents a novel candidate gene for obesity based on its location as well as its function. It encodes a Na- and Cl-dependent membrane protein that transports neutral and cationic amino acids across the plasma membrane (34). Certain amino acid derivatives are essential in appetite regulation. For example, serotonin (5-hydroxytryptamine), that is a neurotransmitter increasing satiety, is synthesized from tryptophan. The rate of serotonin synthesis depends on tryptophan availability in relation to the large neutral amino acids (LNAAs) (35), because tryptophan competes with other amino acids for uptake across the blood-brain barrier (36). Thus, factors affecting amino acid absorption from the intestinal tract or transportation across the plasma membranes into the target cell could potentially affect the tryptophan availability for serotonin synthesis, and further the appetite control. It has been shown that SLC6A14 has a high affinity to tryptophan as well as to some other neutral and cationic amino acids (34). Interestingly, Roca et al. reported a lower tryptophan/LNAA ratio in subjects with high BMI, and this difference was more pronounced in men than in women (37). In addition, both tryptophan hydroxylase, which is a rate-limiting enzyme in serotonin synthesis, and SLC6A14 are expressed in the pituitary gland.

Gender-specific differences in the prevalence of severe obesity (BMI > $\left.35 \mathrm{~kg} / \mathrm{m}^{2}\right)$ are well established. Females are more often affected than males in Finland (38). Even more pronounced are the differences between men and women in obesity-related features such as fat percentage and fat distribution, which are influenced by hormonal factors such as sex steroids and leptin, or differences in fatty acid oxidation and metabolism (12, 13). However, the variants of an $\mathrm{X}$-chromosome gene 
Table 6

The variants identified in the sequencing analysis of the SLC6A14 gene and the adjacent predicted gene, LOC203413.

\begin{tabular}{|c|c|c|c|}
\hline Variants in the $S L C 6 A 14$ gene & $\begin{array}{l}\text { Nucleotide position from } \\
\text { the start site of the SLC6A14 gene }\end{array}$ & Variant & $\begin{array}{c}\text { NCBI SNP Cluster ID } \\
\text { Cluster ID and/or Celera SNP ID }\end{array}$ \\
\hline-715 & -715 & $C / G$ & (novel) \\
\hline-298 & -298 & $A / G$ & (novel) \\
\hline Intron $1+167=S N P 1$ in Table 3 & 303 & $A / T$ & rs2312054, CV15979351 \\
\hline Exon $2+36$ (Gly-Gly) & 1,204 & $A / T$ & (novel) \\
\hline Intron $2+398$ & 1,733 & $A / G$ & (novel) \\
\hline Intron $2+456$ & 1,791 & $C / T$ & (novel) \\
\hline Intron $2+1,341$ & 2,676 & $A / G$ & (novel) \\
\hline Intron $2+2,066$ & 3,401 & $C / T$ & rs5905284, CV343447 \\
\hline Intron $2+2,271$ & 3,605 & $A / G$ & (novel) \\
\hline Intron $2+2,406$ & 3,740 & $A / G$ & (novel) \\
\hline Intron $3+165$ & 4,641 & $C / T$ & rs5905285, CV2521237 \\
\hline Intron $3+890$ & 5,366 & $A / G$ & rs5905176, CV2521238 \\
\hline Intron $3+1,412$ & 5,888 & $C / T$ & rs5905177, CV26290629 \\
\hline Intron $3+1,547$ & 6,023 & $C / T$ & (novel) \\
\hline Intron $5+998$ & 8,167 & $C / T$ & (novel) \\
\hline Intron $5+1041$ & 8,200 & $A / C$ & (novel) \\
\hline Intron $6+811$ & 9,243 & $C / T$ & rs2312055, CV15979352 \\
\hline Intron $6+843$ & 9,273 & $A / G$ & (novel) \\
\hline Intron $6+912$ & 9,342 & $C / G$ & rs2312056, CV15979362 \\
\hline Intron $6+998$ & 9,428 & $C / T$ & rs2312057, CV15979363 \\
\hline Intron $6+1,023$ & 9,453 & $C / T$ & rs4824323 \\
\hline Intron $6+1,027$ & 9,457 & $C / T$ & rs4824324 \\
\hline Intron $6+1,069$ & 9,499 & $A / G$ & rs 4824358 \\
\hline Intron $6+1,074$ & 9,504 & $A / G$ & rs4824359 \\
\hline Intron $6+1,080-1,081$ & 9,510 & $A T / T C$ & (novel) \\
\hline Intron $6+1,085$ & 9,515 & $A / C$ & (novel) \\
\hline Intron $7+565$ & 10,825 & $A / C$ & (novel) \\
\hline Intron $7+587$ & 10,846 & $A / G$ & (novel) \\
\hline Intron $7+1,618$ & 11,877 & $G / T$ & (novel) \\
\hline Intron $7+1,810$ & 12,070 & $C / G$ & (novel) \\
\hline Exon $8+144$ (Ser-Ser $)$ & 14,962 & $C / T$ & (novel) \\
\hline Intron $8+252$ & 15,299 & $C / G$ & (novel) \\
\hline Intron $8+641$ & 15,688 & $A / T$ & (novel) \\
\hline Intron $8+1,049$ & 16,096 & $A / G$ & (novel) \\
\hline Intron $9+95$ & 16,614 & $C / G$ & (novel) \\
\hline Intron $9+713$ & 17,232 & $\mathrm{G} / \mathrm{T}$ & rs 4824325 \\
\hline Intron $10+69$ & 17,890 & $C / G$ & CV2474483 \\
\hline Intron $10+174$ & 17,995 & $\mathrm{C} / \mathrm{T}$ & (novel) \\
\hline Intron $11+82$ & 18,537 & $A / G$ & rs5905287 \\
\hline Intron $12+67$ & 18,912 & $A / G$ & (novel) \\
\hline Intron $12+184$ & 19,029 & $A / G$ & (novel) \\
\hline Intron $12+224$ & 19,068 & $A / T$ & (novel) \\
\hline Intron $12+281$ & 19,125 & $A / C$ & rs5905288 \\
\hline Intron $12+746$ & 19,590 & $C / T$ & rs5905178 \\
\hline Intron $12+1805=S N P 2$ in Table 3 & 20,649 & $C / T$ & rs2071877, CV2474484 \\
\hline Intron $13+170$ & 21,324 & $\mathrm{C} / \mathrm{G}$ & rs2032525, CV2474485 \\
\hline Intron $13+837$ & 21,991 & $A / C$ & rs2011198, CV8789802 \\
\hline Exon $14+325\left(3^{\prime}\right.$-UTR $)=S N P 3$ in Table 3 & 22,510 & $C / G$ & rs2011162, CV8789801 \\
\hline Exon $14+855\left(3^{\prime}\right.$-UTR $)$ & 23,040 & $C / T$ & rs5905289 \\
\hline Exon $14+1,750$ (3'-UTR) & 23,935 & $C / T$ & rs5905179 \\
\hline Exon $14+1,996$ (3'-UTR) & 24,181 & $A / C$ & (novel) \\
\hline Exon $14+2,262\left(3^{\prime}-\right.$ UTR $)$ & 24,447 & $A / G$ & CV2474486 \\
\hline \multicolumn{4}{|l|}{ Variants in the LOC203413 (predicted gene) } \\
\hline Exon $2+297\left(3^{\prime}\right.$-UTR $)$ & 25,089 & $C / T$ & (novel) \\
\hline Intron $1+333$ & 25,822 & $A A A G /-$ & (novel) \\
\hline
\end{tabular}

The SNPs showing initial evidence of association (Table 3) are indicated in bold. A minus sign before the nucleotide indicates that the SNP is located $5^{\prime}$ from the transcription starting site. ID, identifier.

predisposing to obesity may also be involved in the development of these gender-specific differences, as implied by twin data $(14,15)$.

In this study, we utilized the strategy of haplotype mapping and identified a candidate region from which we selected a denser set of SNPs that were genotyped to search for association. A similar approach was previously successful in mapping susceptibility loci for com- plex disorders such as inflammatory bowel disease (39, 40). Previously, we found evidence for linkage between obesity and the region on Xq24 with a single-point MLS of 3.1 with marker DXS6804 (11) located $2.3 \mathrm{Mb}$ from the region showing evidence for association in this study. However, when the study sample was extended and the microsatellite markers were reanalyzed with newer technology using the ABI Prism 3700 
capillary instrument instead of the gel-based $\mathrm{ABI}$ 377XL automated DNA sequencer used in the previous study, the highest single-point MLS of 2.3 was obtained with the SNP1 in the AGTR2 gene located $0.33 \mathrm{Mb}$ from the associated region. The linkage signal on chromosome X emerged largely from the obese male sibpairs (Table 2), which led us to hypothesize that they would provide the best sample for the haplotype analysis. Additionally, since males are hemizygous for X-chromosomes, no bias is introduced to male haplotypes because of missing parental genotype information. Analyses revealed shared haplotypes around the SLC6A14 gene. We tested three SNPs of the SLC6A14 gene for association in an initial case-control study sample. These three SNPs are located in intron 1 $(303 A / T=S N P 1)$, in intron $12(20649 C / T=S N P 2)$, and in the noncoding region of exon $14(22510 C / G=S N P 3)$ (Table 6). The last two SNPs in the 3'-end of the SLC6A14 gene (SNP2 and SNP3) were associated with obesity, as was the SNP haplotype of this gene (Table 3). The obesity-associated haplotype was also the most frequent haplotype in the study sample (frequencies of 0.52 in cases versus 0.33 in controls, respectively).

Next, the two SNPs of the SLC6A14 gene showing evidence of association in the initial association analysis were further tested for association in an independent replication sample of 837 cases and 968 controls from Finland and Sweden, including both females and males. Again significant differences in allele frequencies were observed with SNP3 $(P=0.003)$ (Table 7). We also observed that the obesity-associated allele in the replication study was opposite to the one identified in the initial study (Tables 3 and 5). This may reflect the different haplotype background of the two study populations. It is also possible that the actual causative variant(s) are in LD with the associated variants detected here. Although both Finnish study samples (the original and replication) were collected mostly from the southern part of Finland, the birthplaces of the mothers in the initial study were clustered in the eastern parts of Finland, in the Savo and Karelia regions. The replication sample with its relatively large number of individuals is probably not as regionally biased and represents the general population. Furthermore, the association in the replication study emerged mainly from women. This may reflect two things. On the one hand, the size of the replication study sample should have enabled us to detect differences of this magnitude in allele frequencies (Table 5). On the other hand, our original study sample may not have provided enough power to detect evidence of linkage and shared haplotypes especially in females, because of its small size (184 nuclear families with 80 female sibpairs) and small amount of parental genotype data $(n=59)$ available, whereas in males the haploid X-chromosomal data easily provided this crucial information. It is also possible that some unknown gender-specific factors as well as random $\mathrm{X}$-inactivation affect the results, thus partially explaining these allelic differences.
Based on the current data, we cannot confirm whether the associated variants in the SLC6A14 gene actually predispose to obesity or if the functional variants are in LD with these and located in some other genes close to the SLC6A14 gene, although it is unlikely that the LD would reach very far from the variants studied here, especially in the large replication study sample. Our results are promising, as the association was replicated in an independent study sample. We also sequenced the entire SLC6A14 gene and the adjacent predicted gene, LOC203413. Although a total of 54 variants were identified (Table 6 ), none of the variants has an obvious effect on the protein function (i.e., amino acid exchange or truncated product). Thus, none of the SNPs represents an obvious causative variant such as a nonsense or missense mutation, suggesting that they may instead serve as other regulatory or splicing elements for the SLC6A14 gene or be in LD with an unidentified coding variant of a gene located nearby. Future studies in other obesity samples, preferably linked to this region, are warranted to address the question of the causative variant(s) and could be undertaken prior to functional studies. Other populations could further help restrict the region due to their possibly different underlying LD structure and also because functional studies of noncoding variants are very challenging and should be restricted to a minimum number of SNPs. Furthermore, it is possible that the predisposing variant in the promoter, untranslated region, or intron has a small but significant effect for example on the transcription rate. The predisposing allele could also represent a combination of different variants. However, these effects are difficult to tackle without thorough association studies in several populations.

Interestingly, a recent genome-wide scan for $\mathrm{CHD}$ in Finns revealed a significant evidence for linkage to this same region on Xq23-26, with a two-point lod score of 3.5 (41). Furthermore, the results of that study suggested an initial association with marker DXS8053 $(P=0.007)$, located in the immediate vicinity of the SLC6A14 gene $(30 \mathrm{~kb})$. Since overweight predisposes to $\mathrm{CHD}$, and CHD patients are often obese, it is tempting

\section{Table 7}

Results of the association analysis of the five additional SLC6A14 variants.

\section{The variant in the} SLC6A14 gene

\begin{tabular}{lccc} 
& $\begin{array}{c}\text { Obese } \\
(n=180)\end{array}$ & $\begin{array}{c}\text { Controls } \\
(n=180)\end{array}$ & \\
$-715 C / G$ & $0.72 / 0.28$ & $0.73 / 0.27$ & NS \\
$-298 A / G$ & $0.96 / 0.04$ & $0.97 / 0.03$ & NS \\
$3,401 C / T$ (intron $2+2,066)$ & $0.26 / 0.74$ & $0.28 / 0.72$ & NS \\
$2,3040 C / T$ (exon 14 + 855) & $0.70 / 0.30$ & $0.80 / 0.20$ & $\mathbf{0 . 0 5}$ \\
$2,4447 A / G($ exon 14 +2262$)$ & $0.80 / 0.20$ & $0.81 / 0.19$ & NS \\
\hline
\end{tabular}

Significant $P$ value is indicated in bold. A minus sign before the nucleotide indicates that the SNP is located $5^{\prime}$ from the transcription starting site. 
to hypothesize that allelic variants of the same gene may predispose to both traits.

\section{Acknowledgments}

We wish to warmly thank the patients for participating in this study. Teppo Varilo is greatly appreciated for family history investigation; Janet Sinsheimer and Tero Hiekkalinna are thanked for statistical advice; Jaana Hartiala, Susanna Vikman, Jennifer Schmidt, Ali Kuraishy, Maikki Parkkonen, Arja Tapio, and Tuula Airaksinen are thanked for technical assistance. This study was supported by the Finnish Cultural Foundation, Sigrid Jusélius Foundation, Finnish Heart Foundation, The Center of Excellence in Disease Genetics of the Academy of Finland, the Folkhälsan Research Foundation, The Helsinki University Central Hospital, the Finnish Diabetes Research Foundation, the EC (BM4CT95-0662), the Swedish Medical Research Council, The Novo Nordisk Foundation, the Juvenile Diabetes Foundation - Wallenberg Foundation and Crafoord Foundation, Påhlssons Foundation and Swedish Research Council. This work was performed mainly at the National Public Health Institute in Helsinki under the research program of Molecular Medicine of Biomedicum and at the Department of Human Genetics, David Geffen School of Medicine at UCLA.

1. National Task Force on the Prevention and Treatment of Obesity. 2000. Overweight, obesity and health risk. Arch. Intern. Med. 160:898-904.

2. Stunkard, A.J., Harris, J.R., Pedersen, N.L., and McClearn, G.E. 1990. The body-mass index of twins who have been reared apart. N. Engl. J. Med. 322:1483-1487.

3. Moll, P.P., Burns, T.L., and Lauer, R.M. 1991. The genetic and environmental sources of body mass index variability: the Muscatine Ponderosity Family Study. Am. J. Hum. Genet. 49:1243-1255.

4. Korkeila, M., Kaprio, J., Rissanen, A., and Koskenvuo, M. 1995. Consistency and change of body mass index and weight. A study on 5967 adult Finnish twin pairs. Int. J. Obes. Relat. Metab. Disord. 19:310-317.

5. Echwald, S.M. 1999. Genetics of human obesity: lessons from mouse models and candidate genes. J. Intern. Med. 245:653-666.

6. Chagnon, Y.C., et al. 2003. The human obesity gene map: the 2002 update. Obes. Res. 11:313-367.

7. Iman, P.G. 2000. Obesity as a medical problem. Nature. 404:635-643.

8. Lahti-Koski, M., Jousilahti, P., and Pietinen, P. 2001. Secular trends in body mass index by birth cohort in eastern Finland from 1972 to 1997. Int. J. Obes. Relat. Metab. Disord. 25:727-734.

9. Rissanen, A., Heliövaara, M., Knekt, P., Reunanen, A., and Aromaa, A. 2003. Trends of obesity in Finland 1980-2000. Int.J. Obes. 27:141. (Abstr.)

10. Peltonen, L. 2000. Positional cloning of disease genes: advantages of genetic isolates. Hum. Hered. 50:66-75.

11. Öhman, M., et al. 2000. Genome-wide scan of obesity in Finnish sibpairs reveals linkage to chromosome Xq24. J. Clin. Endocrinol. Metab. 85:3183-3190

12. Wauters, M., and Van Gaal, L. 1999. Gender differences in leptin levels and physiology: a role for leptin in human reproduction. J. Gend. Specif. Med. 2:46-51.

13. Blaak, E. 2001. Gender differences in fat metabolism. Curr. Opin. Clin. Nutr. Metab. Care 4:499-502.

14. Harris, J.R., Tambs, K., and Magnus, P. 1995. Sex-specific effects for body mass index in the new Norwegian twin panel. Genet. Epidemiol. 12:251-265.
15. Pietiläinen, K.H., et al. 1999. Distribution and heritability of BMI in Finnish adolescents aged 16y and 17y: a study of 4884 twins and 2509 singletons. Int. J. Obes. Relat. Metab. Disord. 23:107-115.

16. Hager, J., et al. 1998. A genome-wide scan for human obesity genes reveals a major susceptibility locus on chromosome 10 . Nat. Genet. 20:304-308.

17. Stone, S., et al. 2002. A major predisposition locus for severe obesity, at 4p15-p14. Am. J. Hum. Genet. 70:1459-1468.

18. Price, R.A., Li, W.D., and Kilker, R. 2002. An X-chromosome scan reveals a locus for fat distribution in chromosome region $\mathrm{Xp} 21-22$. Diabetes 51:1989-1991.

19. Deng, H.W., et al. 2002. A genomewide linkage scan for quantitative-trait loci for obesity phenotypes. Am. J. Hum. Genet. 70:1138-1151.

20. Almasy, L., and Blangero, J. 1998. Multipoint quantitative-trait linkage analysis in general pedigrees. Am. J. Hum. Genet. 62:1198-1211.

21. Monaghan, K.G., Van Dyke, D.L., and Feldman, G.L. 1998. Prader-Willilike syndrome in a patient with an Xq23q25 duplication. Am. J. Med. Genet. 80:227-231.

22. Pajukanta, P., et al. 1998. Linkage of familial combined hyperlipidaemia to chromosome 1q21-q23. Nat. Genet. 18:369-373.

23. Soro, A., et al. 2002. Genome scans provide evidence for low-HDL-C loci on chromosomes 8q23,16q24.1-24.2, and 20q13.11 in Finnish families. Am. J. Hum. Genet. 70:1333-1340.

24. Vartiainen, E., et al. 2000. Cardiovascular risk factor changes in Finland 1972-1997. Int. J. Epidemiol. 29:49-56.

25. Lindgren, C.M., et al. 2002. Genomewide search for type 2 diabetes mellitus susceptibility loci in Finnish families: the Botnia study. Am. J. Hum. Genet. 70:509-516.

26. Parker, A., et al. 2001. A gene conferring susceptibility to type 2 diabetes in conjunction with obesity is located on chromosome 18p11. Diabetes. 50:675-680.

27. Schwartz, S., et al. 2000. PipMaker-a web server for aligning two genomic DNA sequences. Genome Research. 10:577-586.

28. Pielberg, G., Olsson, C., Syvänen, A.-C., and Andersson, L. 2002. Unexpectedly high allelic diversity at the KIT locus causing dominant white color in the domestic pig. Genetics. 160:305-311.

29. Kruglyak, L., and Lander, E.S. 1995. Complete multipoint sib-pair analysis of qualitative and quantitative traits. Am. J. Hum. Genet. 57:439-454.

30. Göring, H.H., and Terwilliger, J.D. 2000. Linkage analysis in the presence of errors III: marker loci and their map as nuisance parameters. Am.J. Hum. Genet. 66:1298-1309.

31. Kruglyak, L., Daly, M.J., Reeve-Daly, M.P., and Lander, E.S. 1996. Parametric and nonparametric linkage analysis: a unified multipoint approach. Am. J. Hum. Genet. 58:1347-1363.

32. Terwilliger, J.D. 1995. A powerful likelihood method for the analysis of linkage disequilibrium between trait loci and one or more polymorphic marker loci. Am. J. Hum. Genet. 56:777-787.

33. Lange, K., et al. 2001. Mendel version 4.0: A complete package for the exact genetic analysis of discrete traits in pedigree and population data sets. Am. J. Hum. Genet. 69:1886a.

34. Sloan, J.L., and Mager, S. 1999. Cloning and functional expression of a human $\mathrm{Na}^{+}$and $\mathrm{Cl}-$ dependent neutral and cationic amino acid transporter $\mathrm{B}^{0+}$. J. Biol. Chem. 274:23740-23745.

35. Benton, D. 2002. Carbohydrate ingestion, blood glucose and mood. Neurosci. Biobehav. Rev. 26:293-308.

36. van der Mast, R.C., and Fekkes, D. 2000. Serotonin and amino acids: partners in delirium pathophysiology? Semin. Clin. Neuropsychiatry. 5:125-131.

37. Roca, P., Proenza, A.M., and Palou, A. 1999. Sex differences in the effect of obesity on human plasma tryptophan/large neutral amino acid ratio. Ann. Nutr. Metab. 43:145-151.

38. Lahti-Koski, M., Vartiainen, E., Männistö, S., and Pietinen, P. 2000. Age, education and occupation as determinants of trends in body mass index in Finland from 1982 to 1997. Int. J. Obes. Relat. Metab. Disord. 24:1669-1676.

39. Rioux, J.D., et al. 2001. Genetic variation in the $5 \mathrm{q} 31$ cytokine gene cluster confers susceptibility to Crohn disease. Nat. Genet. 29:223-228.

40. Hugot, J.P., et al. 2001. Association of NOD2 leucine-rich repeat variants with susceptibility to Crohn's disease. Nature. 411:599-603.

41. Pajukanta, P., et al. 2000. Two loci on chromosomes 2 and X for premature coronary heart disease identified in early- and late-settlement populations of Finland. Am. J. Hum. Genet. 67:1481-1493. 